\title{
Tumor-propagating cells and Yap/Taz activity contribute to lung tumor progression and metastasis
}

\author{
Allison N Lau ${ }^{1,2,3}$, Stephen J Curtis ${ }^{1,2,3}$, Christine M Fillmore ${ }^{1,2,3}$, Samuel P Rowbotham ${ }^{1,2,3}$, \\ Morvarid Mohseni ${ }^{1,2,4}$, Darcy E Wagner ${ }^{5}$, Alexander M Beede ${ }^{1,2,3}$, Daniel T Montoro ${ }^{1,2,3}$, \\ Kerstin W Sinkevicius ${ }^{1,2,3}$, Zandra E Walton ${ }^{6,7,8}$, Juliana Barrios ${ }^{1,2,3}$, Daniel J Weiss ${ }^{5}$, \\ Fernando D Camargo ${ }^{1,2,4}$, Kwok-Kin Wong, ${ }^{6,7,8}$ \& Carla F Kim ${ }^{1,2,3, *}$
}

\begin{abstract}
Metastasis is the leading cause of morbidity for lung cancer patients. Here we demonstrate that murine tumor propagating cells (TPCs) with the markers Sca1 and CD24 are enriched for metastatic potential in orthotopic transplantation assays. CD24 knockdown decreased the metastatic potential of lung cancer cell lines resembling TPCs. In lung cancer patient data sets, metastatic spread and patient survival could be stratified with a murine lung TPC gene signature. The TPC signature was enriched for genes in the Hippo signaling pathway. Knockdown of the Hippo mediators Yap1 or Taz decreased in vitro cellular migration and transplantation of metastatic disease. Furthermore, constitutively active Yap was sufficient to drive lung tumor progression in vivo. These results demonstrate functional roles for two different pathways, CD24-dependent and Yap/Taz-dependent pathways, in lung tumor propagation and metastasis. This study demonstrates the utility of TPCs for identifying molecules contributing to metastatic lung cancer, potentially enabling the therapeutic targeting of this devastating disease.
\end{abstract}

Keywords CD24; lung cancer; metastasis; Taz; tumor propagating cells Subject Categories Molecular Biology of Disease; Stem Cells DOI 10.1002/embj.201386082 | Received 25 June 2013 | Revised 25 November 2013 | Accepted 13 December 2013| Published online 4 February 2014

EMBO Journal (2014) 33, 468-481

\section{Introduction}

The average 5-year survival rate for patients diagnosed with lung cancer remains at a strikingly low $16 \%$. The predominant contributor to this statistic is the fact that the vast majority $(\sim 85 \%)$ of patients are diagnosed when their cancer has already progressed beyond a localized state (Siegel et al, 2013). Even for those patients who undergo resection of localized lung cancer, $72 \%$ will later develop lethal metastatic disease (Pisters et al, 2000). In the absence of novel early detection modalities, it is essential to better understand the mechanisms that control progression and metastasis in order to offer new therapeutic options for lung cancer patients.

The mucin-like cell surface adhesion molecule, CD24, has been implicated as a marker and a key regulator of advanced disease in multiple types of cancer, yet with some possibly conflicting results (Lee et al, 2011; Overdevest et al, 2011; Liu et al, 2012). High levels of CD24 detected by immunohistochemistry had a significantly increased likelihood of disease progression and cancer-related death for lung cancer patients (Kristiansen et al, 2003; Lee et al, 2010). Disseminated lung tumor cells from malignant pleural effusions also express CD24 (Yao et al, 2013). On the other hand, CD24-negative/ low membrane expression was significantly correlated with poor differentiation and worse survival in lung cancers (Damelin et al, 2011). In breast cancers, the links between CD24 expression and tumor progression have also differed between studies (Al-Hajj et al, 2003; Shipitsin et al, 2007).

Tumor-propagating cells (TPCs) are tumor cells capable of serially transplanting and recapitulating the tumor phenotype and may contribute to tumor progression and metastasis, yet few studies

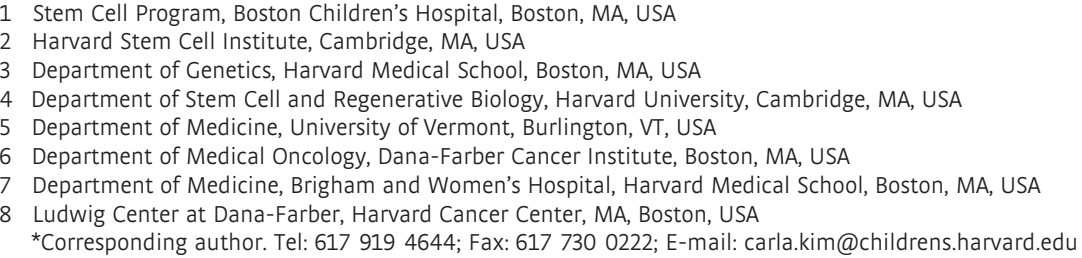


have directly tested this idea. Notable examples have utilized cancer cell lines and xenograft models in breast cancer (Korkaya et al, 2008; Charafe-Jauffret et al, 2009, 2010; Croker et al, 2009), pancreatic (Hermann et al, 2007), and colorectal cancer (Pang et al, 2010) to link metastasis to TPCs. Murine $\mathrm{CD} 24^{+} \mathrm{CD} 90^{+}$TPCs play a key role in breast cancer metastasis through cell autonomous and microenvironmental requirements (Malanchi et al, 2011). However, differentiated, non-tumor propagating cancer cells can also facilitate metastasis in embryonal rhabdomyosarcoma (Ignatius et al, 2012). A CD24-expressing population (CD24 ${ }^{+}$ITGB4 $^{+}$Notch-hi) was shown to be enriched for tumor propagation in a mouse model of lung cancer (Zheng et al, 2013), yet the metastatic potential of this $\mathrm{CD}_{2} 4^{+}$cell population has not been reported.

The Hippo signaling cascade, most noted for its role in organ size control and development, has been posited to play a role in cancer progression (reviewed in Pan, 2010), and emerging evidence supports this concept in lung cancer. Expression of the canonical effector of the Hippo pathway, Yes associated protein 1 (Yap1), has been correlated with poor prognosis in non-small cell lung cancer patients and was shown to modulate the tumorigenicity of human lung cancer cell lines (Wang et al, 2010). Overexpression of WW domain-containing transcription regulator protein 1 (Wwtr1, more commonly referred to as Taz), a close homolog of Yap1, was capable of transforming immortalized human bronchial epithelial cells, while knockdown of Taz in non-small cell lung cancer cell lines decreased tumorigenicity, validating Taz as an oncogene in the lung (Zhou et al, 2011).

Metastatic lung adenocarcinomas, the most common form of lung cancer in patients, can be initiated in mice harboring Lox-StopLox-KrasG12D and p53flox/flox alleles (hereafter, Kras;p53-flox) upon intranasal instillation of adenovirus expressing Cre-recombinase (Jackson et al, 2005). Using this model, we have shown that the $\mathrm{Sca}^{+}$population of tumor cells is enriched for tumor-propagating potential (Curtis et al, 2010). In the present study, we determined that CD24a (the mouse homolog of human CD24, CD24 hereafter) is an additional lung TPC marker and a key mediator of lung cancer cell line migration and subcutaneous tumor propagation. We also show that $\mathrm{Scal}^{+} \mathrm{CD} 24^{+}$cells are enriched for metastatic potential after orthotopic delivery of tumor cells. Lung TPCs exhibit transcriptional profiles correlating with metastatic potential and poor patient prognosis. Finally, our data point to a functional role for YAP and TAZ in lung cancer progression and metastasis.

\section{Results}

\section{CD24 expression marks cells with tumor-propagating capacity}

We sought to identify additional cell surface markers of the $\mathrm{Sca}^{+}$Kras;p53-flox cancer cells we previously identified as lung TPCs. DAPI ${ }^{-} \mathrm{CD} 1^{-} \mathrm{CD}^{-} 5^{-} \mathrm{Sca}^{+}\left(\mathrm{Sca}^{+}\right.$hereafter $)$and $\mathrm{DAPI}^{-} \mathrm{CD}^{-} 1^{-} \mathrm{CD}_{4} 5^{-} \mathrm{Sca}^{-}{ }^{-}$(Sca1 ${ }^{-}$hereafter) cell populations from four primary Kras;p53-flox lung tumors were isolated via fluorescence activated cell sorting (FACS) as previously described (Curtis et al, 2010) and their transcriptional profiles were analyzed by Affymetrix microarray. Expression levels of cell surface markers were examined followed by quantitative real-time PCR (qPCR) and FACS analysis to identify candidate lung TPC markers. Differential expression of Scal (LY6A) in TPCs was confirmed (fold change in $\mathrm{Scal}^{+}$versus Sca1 $\left.{ }^{-}, 30.77\right)$ in this data set. CD133, a putative marker of human lung cancer cells with increased tumorigenicity (Chen et al, 2008; Eramo et al, 2008; Levina et al, 2008; Bertolini et al, 2009), was highly expressed in Scal ${ }^{+}$TPCs by microarray and qPCR analysis (fold change, 23.63) (Curtis et al, 2010), yet flow cytometry for $\mathrm{CD} 133$ failed to show enrichment within the $\mathrm{Sca}^{+}$fraction (unpublished observations). Several other markers of aggressive cancer stem cells in other tissues, including CD44 and CXCR4, were not significantly differentially expressed in $\mathrm{Sca}^{+}$and $\mathrm{Sca}^{-}$cells. Interestingly, CD24 was upregulated in lung TPCs (fold change, 1.8). qPCR confirmed that CD24 was overexpressed more than 3-fold in $\mathrm{Sca1}^{+}$TPCs from Kras;p53-flox lung tumors compared to Sca ${ }^{-}$cells $(P=0.0057)$ (Fig $\left.1 \mathrm{~A}\right)$. Flow cytometric analysis of Kras;p53-flox lung tumor cell preparations revealed that $87.1 \pm 5.44 \%$ of $\mathrm{Scal}^{+}$cells were CD24 ${ }^{+}$(Fig 1B, $n=7$ ).

We utilized our orthotopic intratracheal transplantation model (Curtis et al, 2010) to verify that CD24-expressing cells were lung TPCs. Primary Kras;p53-flox lung tumors were isolated for digestion, FACS, and transplantation. We first compared the activity of $\mathrm{DAPI}^{-}$ $\mathrm{CD} 31^{-} \mathrm{CD}_{4} 5^{-} \mathrm{CD} 24^{+}$cells (hereafter $\mathrm{CD} 24^{+}$) with the activity of $\mathrm{DAPI}^{-} \mathrm{CD} 31^{-} \mathrm{CD}^{-} 5^{-} \mathrm{CD} 24^{-}$cells $\left(\mathrm{CD} 24^{-}\right) \cdot 10,000 \mathrm{CD} 24^{+}$or $\mathrm{CD} 24^{-}$ cells were transplanted intratracheally into immunocompromised Foxn $1^{\text {nu/nu }}$ (nude) mice. Recipient mice were observed until they exhibited labored breathing, when mice were euthanized for analysis of lung tumors $\left(22 \pm 3\right.$ weeks for $\mathrm{CD}_{2} 4^{+}$cells, $25 \pm 4$ weeks for $\mathrm{CD} 24^{-}$cells). The $\mathrm{CD} 24^{+}$and $\mathrm{CD} 24^{-}$populations both propagated lung adenocarcinomas that accurately recapitulated primary Kras; p53-flox tumors (Fig 1C and D). 100\% of recipient mice developed at least one lung tumor after transplantation of $10,000 \mathrm{CD}_{2} 4^{+}$or CD24- cells (10/10 for $\mathrm{CD} 24^{+}$and $12 / 12$ for $\mathrm{CD}^{-} 4^{-}$) (Table S1). Histological analysis revealed that while $\mathrm{CD} 24^{+}$recipient mice had an average of 17 tumors, $\mathrm{CD} 24^{-}$recipients had only four $\left(P=1.2 \times 10^{-4}\right)$, and likewise $\mathrm{CD} 24^{+}$recipients showed $72 \%$ tumor burden (lung area filled with tumor) in contrast to $19 \%$ tumor burden observed for $\mathrm{CD} 24^{-}$recipients $\left(P=8.3 \times 10^{-5}\right)$ (Fig $1 \mathrm{E}$ and $\mathrm{F}$ ).

We next tested the ability of cell populations separated by CD24 expression to serially passage tumors. Interestingly, lung tumors in recipient mice contained a $\mathrm{CD} 24^{+}$population regardless of whether $\mathrm{CD}_{24}{ }^{+}$or $\mathrm{CD} 24^{-}$cells were transplanted despite $\sim 95 \%$ cell purity at the time of tumor cell isolation (Supplementary Fig S1A and B). 1,000 or $10,000 \mathrm{CD} 24^{+}$or $\mathrm{CD} 24^{-}$cells from secondary tumors were FACS-sorted and transplanted orthotopically to test for serial tumor formation ability. Recipients of $\mathrm{CD} 24^{-}$cells from secondary tumors did not develop lung tumors $(0 / 9$ and $0 / 15$ for 1,000 and 10,000 cells, respectively). In contrast, $\mathrm{CD} 24^{+}$cells from secondary tumors could form tertiary tumors. $\mathrm{CD} 24^{+}$cells from secondary tumors yielded tumors in $1 / 7$ mice after transplantation of 1,000 cells and in $6 / 14$ mice after transplantation of 10,000 cells, $P=0.0063$ (Fig $1 \mathrm{G}$ and H, Supplementary Fig S1C and D, Supplementary Table S2). These data supported our hypothesis that CD24 is a marker of lung cancer cells with tumor-propagating capacity.

We next used the combination of Sca1 and CD24 to further delineate Kras;p53-flox TPCs. Limiting dilution transplantation experiments were used to compare TPC activity in the $\mathrm{Sca} 1^{+} \mathrm{CD} 24^{+}$, $\mathrm{Sca}^{-} \mathrm{CD}_{2} 4^{+}, \mathrm{Sca}^{+} \mathrm{CD} 24^{-}$and $\mathrm{Sca} 1^{-} \mathrm{CD} 24^{-}$fractions. Recipients of $\mathrm{Scal}^{+} \mathrm{CD}_{2} 4^{+}$and $\mathrm{Sca} 1^{-} \mathrm{CD} 24^{+}$tumor cells had higher rates of tumor formation than $\mathrm{Sca} 1^{-} \mathrm{CD} 24^{-}$and $\mathrm{Sca}^{+} \mathrm{CD} 24^{-}$recipients, 
A

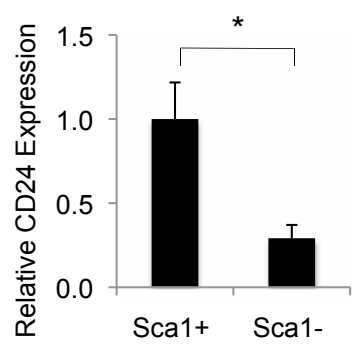

C

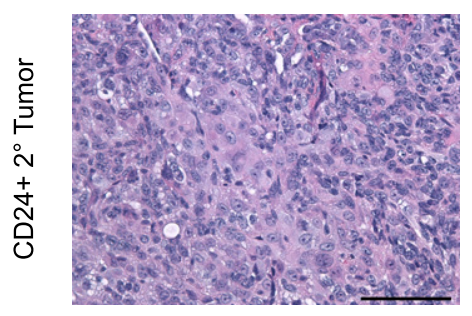

E

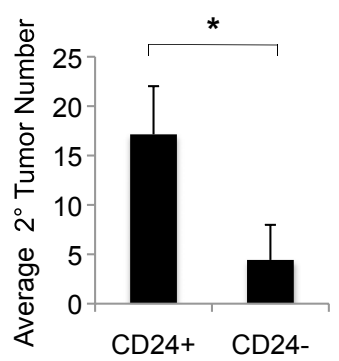

G

\begin{tabular}{|c|c|c|c|}
\hline & \multicolumn{3}{|c|}{ Number of $2^{\circ}$ cells transplanted } \\
\hline & 1,000 & 10,000 & \\
\hline $\begin{array}{l}\text { Cell } \\
\text { Type }\end{array}$ & $\begin{array}{l}\text { No. mice with } \\
\text { tumors / No. } \\
\text { transplanted (\%) }\end{array}$ & $\begin{array}{c}\text { No. mice wit } \\
\text { tumors / No. } \\
\text { transplanted ( }\end{array}$ & \\
\hline $\begin{array}{c}2^{\circ} \\
\text { CD24+ }\end{array}$ & $\begin{array}{c}1 / 7 \\
(14.2 \%)\end{array}$ & $\begin{array}{c}6 / 14 \\
(42.9 \%)\end{array}$ & * \\
\hline $\begin{array}{l}2^{\circ} \\
\text { CD24- }\end{array}$ & $\begin{array}{c}0 / 9 \\
(0 \%)\end{array}$ & $\begin{array}{l}0 / 15 \\
(0 \%)\end{array}$ & \\
\hline
\end{tabular}

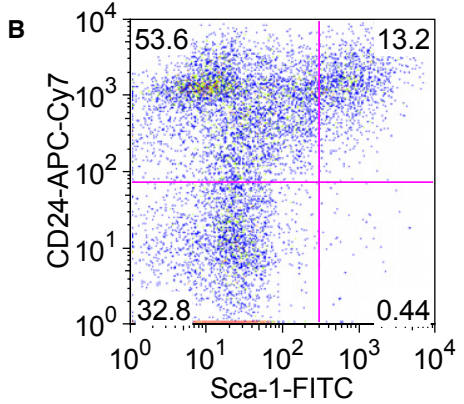

D

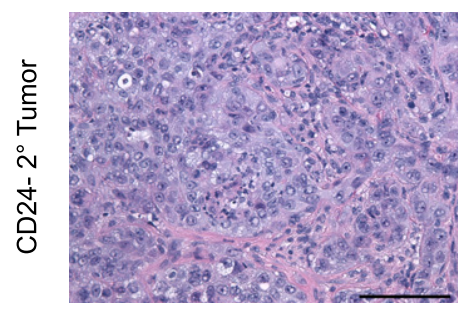

F

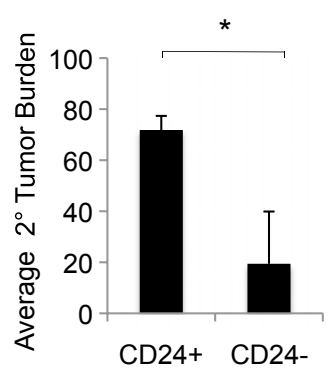

H

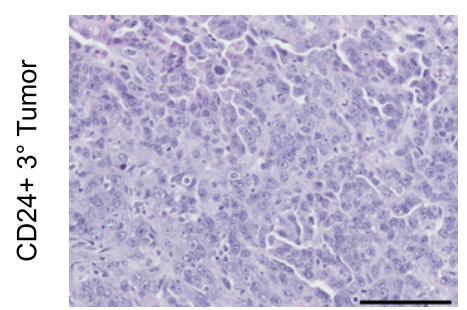

Figure 1. CD24 marks cells enriched for tumor-propagating ability.

A Real Time RT-PCR analysis for $\mathrm{CD} 24$ in sorted $\mathrm{Sca1}^{+}$and $\mathrm{Sca}^{-} \mathrm{Kras} ; \mathrm{p53}$-flox lung tumor cells.

B A representative flow cytometry plot showing CD24 and Sca1 expression in Kras;p53-flox lung tumor cells. Cells shown were gated on the single, live (DAPInegative), CD31-negative, CD45-negative population.

C, D H\&E images showing a secondary Kras;p53-flox lung adenocarcinoma from the transplantation of CD24 tumor cells (C) or CD24 $4^{-}$tumor cells (D). 200x magnification, scale bar $=100 \mu \mathrm{m}$.

E, F Quantification of tumors from transplantation of $10,000 \mathrm{CD}_{2} 4^{+}$or $\mathrm{CD}_{2} 4^{-}$cells. Average tumor number per recipient mouse $(\mathrm{E}), n=7$ for each cell type transplanted). Average tumor burden in secondary mice calculated as the percentage of lung area filled with tumors ( $F, n=6$ for $\mathrm{CD}_{2} 4^{+}, n=7$ for $\mathrm{CD}_{2} 4^{-}$).

G Table showing tertiary tumor formation ability of $\mathrm{CD} 24^{+}$and $\mathrm{CD} 24^{-}$Kras;p53-flox lung tumor cells from secondary transplants. 1,000 or $10,000 \mathrm{CD}^{-} 4^{+}$or $\mathrm{CD} 24^{-}$ cells were intratracheally transplanted into immunocompromised mice. The percentage of recipient mice with at least one lung tumor after 13-28 weeks is shown. ${ }^{*} P=0.0063$, Fishers Exact Test, two-tailed.

H H\&E image showing a tertiary Kras;p53-flox lung adenocarcinoma from the transplantation of CD24 $4^{+}$tumor cells.

Data information: In (A, E and F): ${ }^{*} P<0.05$. See also Supplementary Fig S1 for additional data. 
A

\begin{tabular}{|c|c|c|c|c|}
\hline & \multicolumn{4}{|c|}{ Number of cells transplanted } \\
\hline & 100 & $1,000-6,000$ & $6,000-10,00$ & \\
\hline Cell Type & $\begin{array}{c}\text { No. mice with } \\
\text { tumors / No. } \\
\text { transplanted (\%) }\end{array}$ & $\begin{array}{c}\text { No. mice with } \\
\text { tumors / No. } \\
\text { transplanted (\%) }\end{array}$ & $\begin{array}{c}\text { No. mice wi } \\
\text { tumors / Nc } \\
\text { transplanted }\end{array}$ & \\
\hline Sca1+/ CD24+ & $\begin{array}{c}3 / 18 \\
(16.7 \%)\end{array}$ & $\begin{array}{c}2 / 14 \\
(14 \%)\end{array}$ & $\begin{array}{c}9 / 16 \\
(56 \%)\end{array}$ & \\
\hline Sca1-/ CD24+ & $\begin{array}{l}0 / 17 \\
(0 \%)\end{array}$ & $\begin{array}{c}4 / 13 \\
(31 \%)\end{array}$ & $\begin{array}{l}12 / 17 \\
(71 \%)\end{array}$ & * \\
\hline Sca1+/ CD24- & $\begin{array}{c}1 / 18 \\
(5.6 \%) \\
\end{array}$ & $\begin{array}{c}0 / 7 \\
(0 \%)\end{array}$ & $\begin{array}{c}1 / 5 \\
(20 \%) \\
\end{array}$ & \\
\hline Sca1-/ CD24- & $\begin{array}{l}0 / 18 \\
(0 \%) \\
\end{array}$ & $\begin{array}{c}2 / 12 \\
(17 \%) \\
\end{array}$ & $\begin{array}{c}6 / 18 \\
(33 \%)\end{array}$ & \\
\hline
\end{tabular}

B

\begin{tabular}{|c|c|}
\hline \multirow[t]{2}{*}{ B } & $\begin{array}{l}\text { Number of } 2^{\circ} \\
\text { cells transplanted }\end{array}$ \\
\hline & 10,000 \\
\hline Cell Type & $\begin{array}{c}\text { No. mice with } \\
\text { tumors / No. } \\
\text { transplanted (\%) }\end{array}$ \\
\hline Sca1+/ CD24+ & $\begin{array}{c}2 / 5 \\
(40 \%)\end{array}$ \\
\hline Sca1-/ CD24+ & $\begin{array}{c}3 / 4 \\
(75 \%)\end{array}$ \\
\hline Sca1+/ CD24- & N/A \\
\hline Sca1-/ CD24- & $\begin{array}{c}0 / 5 \\
(0 \%)\end{array}$ \\
\hline
\end{tabular}

C

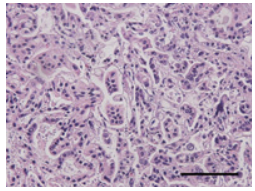

Sca1+CD24+

Lung Tumor, Grade 4 Kidney Metastasis
D

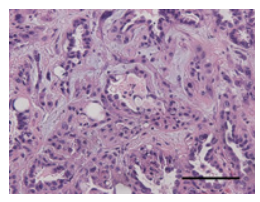

Sca1-CD24+ Lung Tumor, Grade 4 Chest Metastasis

E

$6,000-10,000$ cells

\begin{tabular}{|c|c|c|c|c|}
\hline \multirow[b]{2}{*}{ Cell Type } & \multirow[b]{2}{*}{\begin{tabular}{||c} 
No. mice with \\
mets. / No. mice \\
with tumors (\%)
\end{tabular}} & \multicolumn{3}{|c|}{ Location } \\
\hline & & $\begin{array}{l}\text { Pleural Lining/ } \\
\text { Chest Cavity }\end{array}$ & Lymph node & Distant \\
\hline Sca1+/ CD24+ & $\left.\begin{array}{c}6 / 7 \\
(86 \%)\end{array}\right] *$ & $\begin{array}{c}6 / 6 \\
(100 \%) \\
\end{array}$ & $\begin{array}{c}3 / 6 \\
(50 \%) \\
\end{array}$ & $\begin{array}{c}1 / 6 \text { kidney } \\
(17 \%)\end{array}$ \\
\hline Sca1-/ CD24+ & $\begin{array}{l}3 / 10 \\
(30 \%)\end{array}$ & $\begin{array}{c}3 / 3 \\
(100 \%)\end{array}$ & $\begin{array}{c}0 / 3 \\
(0 \%)\end{array}$ & $\begin{array}{c}0 / 3 \\
(0 \%)\end{array}$ \\
\hline
\end{tabular}

$\mathbf{F}$

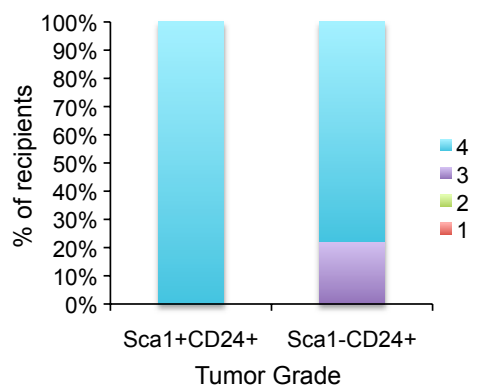

Figure 2. Sca1 and CD24 mark cells in Kras;p53-flox tumors with metastatic potential after orthotopic transplantation.

A Table showing tumor propagation ability of Sca1 ${ }^{+} \mathrm{CD} 24^{+}, \mathrm{Sca}^{-} \mathrm{CD} 24^{+}, \mathrm{Sca}^{+} \mathrm{CD} 24^{-}$and Sca1 ${ }^{-} \mathrm{CD} 24^{-}$Kras;p53-flox lung tumor cells. 100-10,000 cells were intratracheally transplanted into immunocompromised mice. The percentage of recipient mice with at least one lung tumor after 17-33 weeks is shown.

B Table showing tertiary tumor formation ability of Sca1 ${ }^{+} \mathrm{CD} 24^{+}$, Sca ${ }^{-} \mathrm{CD} 24^{+}$, and Sca1 ${ }^{-} \mathrm{CD} 24^{-}$Kras;p53-flox lung tumor cells from secondary transplants: 10,000 $\mathrm{CD}_{24}{ }^{+}$or $\mathrm{CD}_{24}^{-}$cells were intratracheally transplanted into immunocompromised mice. The percentage of recipient mice with at least one lung tumor after 20-29 weeks is shown.

C H\&E images showing a lung tumor (left) and kidney metastasis (right) from the transplantation of Sca1 $1^{+}$CD24 $4^{+}$tumor cells. 200× magnification, scale bars $=100 \mu \mathrm{m}$.

D H\&E images showing a lung tumor (left) and chest cavity metastasis (right) from the transplantation of Sca1 ${ }^{-} \mathrm{CD} 24^{+}$tumor cells. 200× magnification, scale bars $=100 \mu \mathrm{m}$.

E Table of metastatic incidence in secondary mice from transplantation of 6,000-10,000 Sca1 ${ }^{+} \mathrm{CD} 24^{+}, \mathrm{Sca1}^{-} \mathrm{CD} 24^{+}$, Sca1 ${ }^{+} \mathrm{CD} 24^{-}$and Sca1 ${ }^{-} \mathrm{CD} 24^{-} \mathrm{Kras}^{-} \mathrm{p53-flox}$ lung tumor cells. The number and (percentage) of recipient mice with at least one metastatic lesion are shown in the first column. Location columns show the number and (percentage) of recipient mice with metastases in the noted site.

$\mathrm{F}$ The percentage of recipient mice bearing lung tumors from transplantation of Sca1 ${ }^{+} \mathrm{CD} 24^{+}(n=7)$ or $\mathrm{Scal}^{-} \mathrm{CD} 24^{+}(n=9)$ cells with the indicated tumor grade (Scale 1-4) is shown. Grade 1 or 2 lesions were not observed in recipient mice.

further showing $\mathrm{CD} 24$ is a TPC marker $\left(\mathrm{Sca1}^{-} \mathrm{CD} 24^{+}\right.$vs Sca1 ${ }^{-} \mathrm{CD} 24^{-}, \quad P=0.0116, \quad$ Sca ${ }^{-} \mathrm{CD} 24^{+}$versus $\mathrm{Sca}^{+} \mathrm{CD} 24^{-}$, $P=0.0334$ ) (Fig 2A). Similar to our results using CD24 alone,
Sca1 ${ }^{+} \mathrm{CD} 24^{+}$and $\mathrm{Scal}^{-} \mathrm{CD} 24^{+}$cells serially propagated tumors $\left(2 / 5\right.$ and $3 / 4$ mice respectively), while $\mathrm{Sca} 1^{-} \mathrm{CD} 24^{-}$could not $(0 / 5)$

(Fig 2B). Importantly, cytospin and GPCR showed the four 
Sca1/CD24-sorted populations had similar epithelial cell content (Supplementary Fig S2A,B,C and D). Thus, Sca1 ${ }^{+} \mathrm{CD}_{2} 4^{+}$and $\mathrm{Sca}^{-}{ }^{-} \mathrm{CD} 24^{+}$cells are enriched for Kras;p53-flox TPCs.

\section{$\mathrm{Sca1}^{+} \mathrm{CD} 4^{+}$status correlates with metastatic potential}

Orthotopically transplanted Kras;p53-flox tumor cell populations also produced metastases in recipient mice, allowing us to also test the role of TPCs in metastasis. First, a cohort of $\mathrm{CD} 24^{+}$and $\mathrm{CD} 24^{-}$ cell recipients were euthanized for collection of tissues from common metastatic sites for lung cancer, including connective tissue in the pleural cavity, lymph nodes, heart, liver, spleen and adrenal glands. To more fairly compare metastatic capacity, we analyzed CD24- ${ }^{-}$cell recipients 26-29 weeks after transplantation, when they had primary tumors of similar size and grade as tumors in $\mathrm{CD} 24^{+}$cell recipients analyzed at 22 weeks (Supplementary Fig S1G and H). It is possible that larger tumors are more likely to give rise to metastases than smaller tumors. Therefore, we only assessed metastasis in recipient mice bearing lung tumors of similar size. With these parameters, there was no significant difference in metastasis in recipients of $\mathrm{CD} 24^{+}$cells versus $\mathrm{CD}_{2} 4^{-}$cells (Supplementary Fig S1E). $\mathrm{CD} 24^{+}$cell recipients developed metastatic lesions in the chest wall, local lymph nodes, and the heart (Supplementary Fig S1E and F). Similarly, mice that received $\mathrm{CD} 24^{-}$cells developed small chest cavity lesions and local lymph node metastases yet did not have metastatic lesions in the heart. Thus, CD24 status alone is not sufficient as a metastatic marker.

Having identified the $\mathrm{Sca}^{+} \mathrm{CD} 24^{+}$and $\mathrm{Sca} 1^{-} \mathrm{CD} 24^{+}$populations as TPC-enriched, we tested their relative metastatic capability. Recipients of $\mathrm{Sca}^{+} \mathrm{CD} 24^{+}$or $\mathrm{Sca} 1^{-} \mathrm{CD} 24^{+}$populations developed high-grade lung tumors and metastases (Fig 2C and D). When we compared mice bearing lung tumors of equal size and comparable grades that arose from either of the TPC populations, recipients of $\mathrm{Scal}^{+} \mathrm{CD} 24^{+}$cells $(6 / 7)$ were significantly more likely to have metastases than the Sca1 ${ }^{-} \mathrm{CD} 24^{+}$recipients $(3 / 10) \quad(P=0.0498$, Fig $2 \mathrm{E}$ and F, Supplementary Fig S2E). Thus, at least two TPC populations can be identified with Sca1 and CD24 staining, and the $\mathrm{Scal}^{+} \mathrm{CD} 24^{+}$phenotype is most highly associated with metastatic activity.

\section{CD24 plays a functional role in metastatic activity}

To further probe the role of CD24 in the metastatic spread of lung cancer, we generated a series of cell lines from the Kras;p53-flox lung adenocarcinoma model. The CK1750 and SC241 cell lines exhibit many properties of metastatic lung tumor cells. Firstly, CK1750 cells robustly formed adenocarcinomas when transplanted intratracheally (10/12 recipients formed tumors when 1,000-10,000 cells were injected) (Fig 3A). Furthermore, these recipient animals developed metastases in multiple sites including the chest wall $(5 / 10)$, lymph nodes (4/10), adrenal glands $(2 / 10)$, and liver $(1 / 10)$, with approximately $50 \%$ of recipients exhibiting metastasis to one or more sites (Fig 3A). Nearly all CK1750 and SC241 cells expressed CD24 and Sca1 (Fig 3B). Thus, the cell lines functionally and phenotypically resembled the most metastatic Kras;p53-flox lung TPCs.

Utilizing two different shRNA constructs against CD24 (shCD24-1 targets the 3' UTR, while shCD24-5 targets the coding region) we diminished CD24 expression to $\sim 20-30 \%$ of normal transcript levels compared to shGFP control cells after selection for CK1750 and SC241 cells expressing the lowest levels of CD24 by FACS (termed "Low") (Supplementary Fig S3A). Importantly, knockdown of CD24 in the CK1750 cell line did not affect the growth of the cells in standard cell culture conditions (Supplementary Fig S3B). However, in transwell in vitro migration assays, the CD24 knockdown lines showed markedly less migration compared with control shGFP cells (Fig 3C); the shCD24-Low-1 and shCD24-Low-5 lines showed a 3 -fold and 4-fold reductions in migration, respectively $(P=0.033$ \& $P=0.015)$. CD24 knockdown in SC241 cells showed similar results; the shCD24-Low-1 and shCD24-Low-5 lines also showed 3-fold and 4-fold reductions in migration, respectively $(P=0.013$ \& $P=0.0024$ ) (Supplementary Fig S3C). To assess metastatic capacity in vivo, shGFP and shCD24 cells were injected into the tail vein of nude mice. Transplantation of the shCD24-Low-1 and shCD24-Low-5 lines resulted in a significantly lower number of lung metastases $\left(P=0.7 \times 10^{-4}\right.$ and $\left.P=0.027\right)$ and smaller tumor burden for shCD24-Low-1 transplants (Fig 3D, Supplementary Fig S3D and E). However, average tumor size was not significantly different between the shGFP control and shCD24 groups, suggesting engraftment rather than proliferation is affected by knockdown of CD24 in this tail vein assay (Supplementary Fig S3F). Intratracheal injections showed that shCD24 cells were devoid of TPC activity compared with shGFP controls; shCD24-Low-1 cells produced lung tumors after IT administration in 0/5 recipients whereas shGFP cells yielded tumors in $4 / 6$ recipients $(P=0.04$, Fig $3 \mathrm{E}$ ). While CD24 knockdown cells were capable of subcutaneous tumor formation, the shCD24Low-1 line showed a longer latency to first palpable tumor $(P=0.04)$ and yielded smaller tumors 3 weeks post-transplant $(P=0.001)$ (Supplementary Fig S3G). These findings strongly suggest that CD24 plays a functional role in TPC activity and in promoting lung cancer metastasis.

\section{Murine lung TPCs exhibit clinically relevant, metastatic gene expression profiles}

To better understand the connections between TPCs and metastatic potential, we next took an unbiased gene expression profiling approach. Microarray data from the Kras;p53-flox TPCs were further interrogated by bioinformatics. 278 differentially expressed, upregulated probes corresponding to 250 unique genes ( $\log _{2}$ fold-change $>$ 1.53 and $P$-value $\leq 0.02$ ) were used in this analysis (Fig $4 \mathrm{~A}$ and Supplementary Data). Gene set enrichment analysis (GSEA) on the expression data revealed that gene sets involved in processes such as cytoskeletal rearrangement, cell motility/migration, and invasion, all of which are associated with metastatic capacity, were significantly overrepresented in TPCs (Fig 4B). Sca1 ${ }^{+}$and Sca1 ${ }^{-}$populations had equally low levels of vimentin (Vim) expression and high levels of E-cadherin (Cdh1) (Supplementary Fig S4A and B), confirming that enrichment for these gene sets was not a result of stromal contamination. These results supported the idea that lung TPCs are involved in metastatic spread of Kras;p53-flox lung tumors, and that this activity is not related to an epithelial-to-mesenchymal transition as observed in other tumor types (Cordenonsi et al, 2011).

As we had found increasing evidence that TPCs contributed to metastasis, we sought to determine a relationship between murine TPCs and lung adenocarcinoma patient data. We generated a gene signature consisting of 126 human orthologs corresponding to the 
A

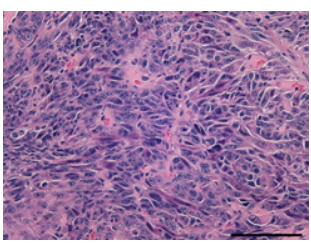

CK1750 Kras; p53-flox cell line lung tumor

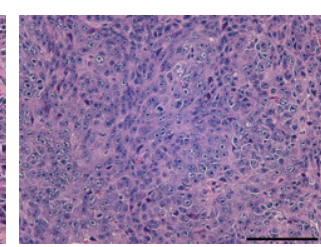

CK1750 Kras; p53-flox cell line metastasis
B

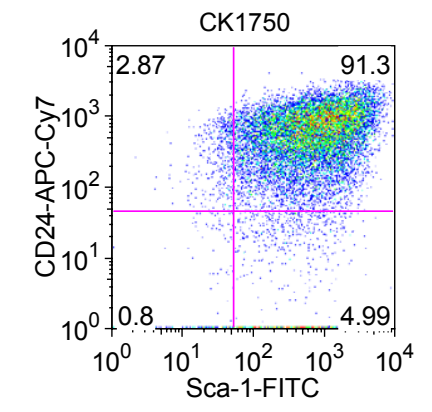

*

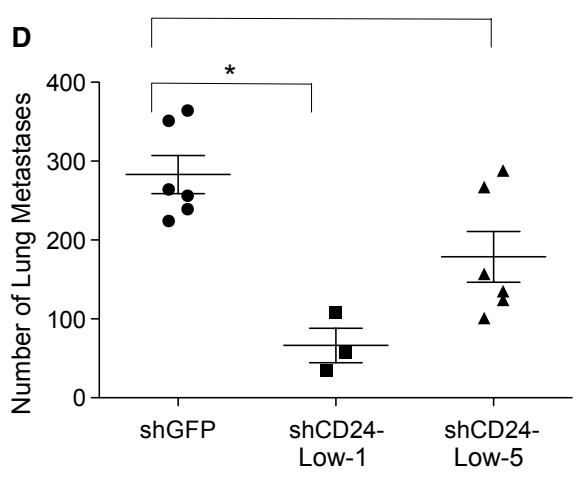

$\mathbf{C}$

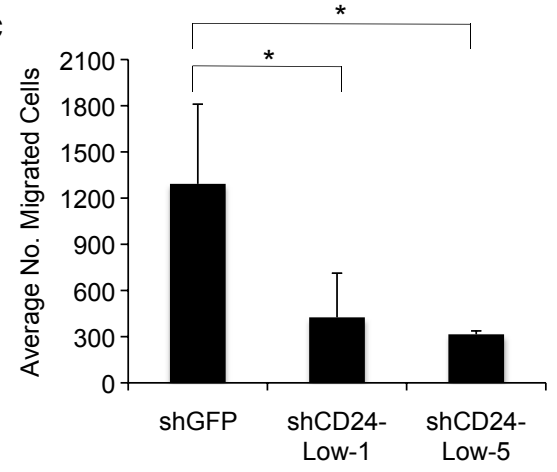

E

\begin{tabular}{c|c}
\hline Treatment & $\begin{array}{c}\text { Lung Tumor } \\
\text { Incidence }\end{array}$ \\
\hline shGFP IT & $\begin{array}{c}4 / 6 \\
(66.7 \%)\end{array}$ \\
\hline shCD24-Low-1 IT & $0 / 5$ \\
& $(0 \%)$ \\
\hline
\end{tabular}

Figure 3. CD24 expression is required for migration and ectopic growth of murine lung adenocarcinoma cells.

A H\&E images of a lung tumor (left) and adrenal gland metastasis (right) from intratracheal transplantation from the Kras;p53-flox CK1750 cell line. Images are 200× magnification, scale bars $=100 \mu \mathrm{M}$.

B FACS plot from CK1750 cells showing expression of CD24 and Sca1. Cells shown were gated on the single, live (DAPI-negative), CD31-negative, CD45-negative population.

C Analysis of cellular migration from in vitro transwell migration assays, determined by scoring cells migrating towards serum-containing (10\% FBS) media with CK1750 CD24 knockdown cells (shCD24-Low-1 \& Low-5, $n=3$ ) or control CK1750 shGFP cells (shGFP, $n=6$ ). Results shown are the average of three independent experiments.

D Average number of lung metastases after tail vein injection of CK1750 shGFP cells (circles), CK1750 shCD24-Low-1 cells (squares), or CK1750 shCD24-Low-5 cells (triangles). Lungs were analyzed for metastases 2 weeks after injection of 500,000 cells. Each symbol represents an individual mouse analyzed.

E Table showing the number of recipient mice with lung tumor formation after intratracheal injection with 100,000 shGFP cells or shCD24-Low-1 cells out of the total injected mice (percentage).

Data information: * $P<0.05$. See also Supplementary Fig S3 for additional data.

significantly upregulated genes in Kras;p53-flox TPCs (Supplementary Data). The TPC gene signature was examined in the Director's Challenge cohort of lung adenocarcinoma patients and was found to be significantly associated with decreased overall survival $(P=0.0006)$ and with metastasis $(P=0.049)$ (Fig $4 C)$. This indicated that our results using murine models to study tumor propagation and metastasis are applicable to human lung cancer.

\section{Yap/Taz in metastatic lung TPCs}

We next used the gene expression analyses to identify molecules other than CD24 that may be crucial for lung tumor propagation and metastatic potential. The gene sets enriched in lung TPCs, including Actin Filament Based Processes, Actin Cytoskeleton Organization and Biogenesis, and Regulation of Cell Migration, included members of the Hippo signaling cascade (Fig 4B). Furthermore, GSEA with a Yap/Taz Gene Signature (Cordenonsi et al, 2011) revealed that $\mathrm{Sca}^{+}{ }^{+}$TPCs were significantly enriched for this gene set; 25 out of 52 genes in the Yap/Taz gene set exhibited core enrichment in lung TPCs (Supplementary Fig S4C).

We validated expression differences in Hippo pathway components in lung TPCs. Yap1 was not significantly differentially expressed between the $\mathrm{Scal}^{+}$and $\mathrm{Scal}^{-}$cells by Real Time RT-PCR analysis (Fig 4D, P=0.10). However, Wwtr1 (Taz), 
A
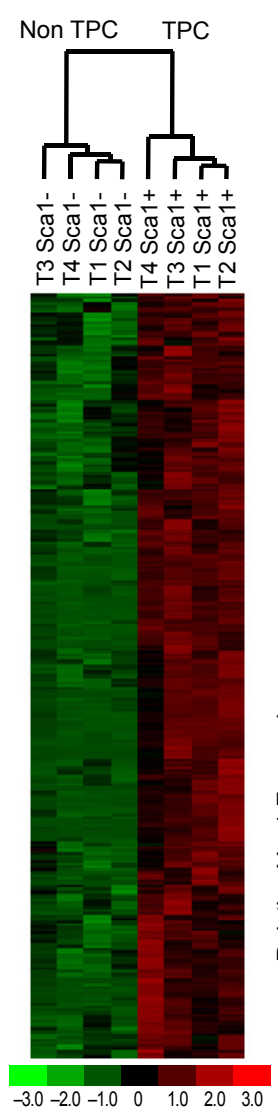

B

\begin{tabular}{|c|c|c|c|}
\hline Gene Set & Enrichment Score & FDR Q-Value & Hippo Genes \\
\hline Cell Projection & 0.564 & 0.0147 & TGFB2 \\
\hline Actin Filament Based Process & 0.550 & 0.0148 & LATS1, NF2, TNNT2 \\
\hline $\begin{array}{c}\text { Actin Cytoskeleton Organization and } \\
\text { Biogenesis }\end{array}$ & 0.555 & 0.0154 & $\begin{array}{c}\text { LATS1, NF2, FLNA, } \\
\text { FSCN1 }\end{array}$ \\
\hline Regulation of Cell Migration & 0.671 & 0.0205 & NF2 \\
\hline Regulation of Cell Morphogenesis & 0.752 & 0.0208 & N/A \\
\hline
\end{tabular}

C
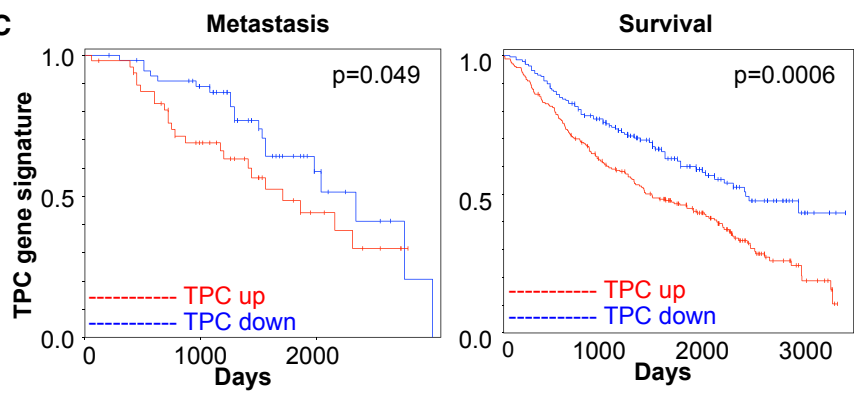

D

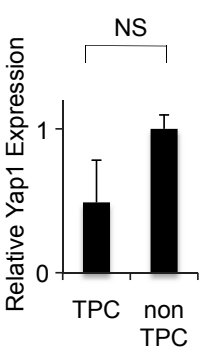

E

$\mathbf{F}$

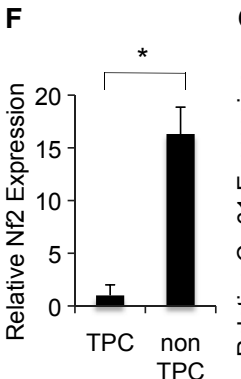

G

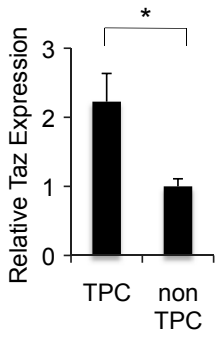

Metastasis

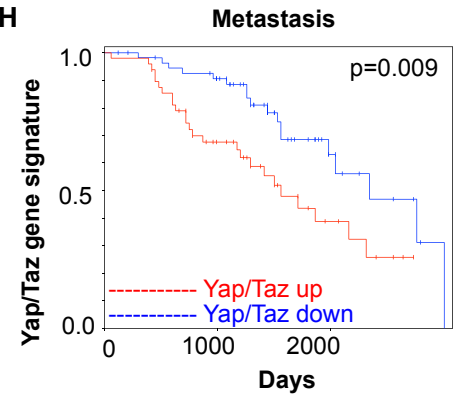

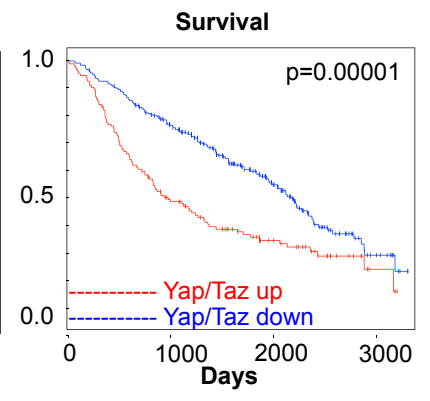

Figure 4. Lung tumor-propagating cells exhibit clinically relevant gene expression profiles that suggest metastatic potential.

A Heatmap showing the 250 genes significantly upregulated in Sca1 ${ }^{+}$TPCs compared to Sca1 ${ }^{-}$non-TPCs from Kras;p53-flox lung tumors as assessed by Affymetrix Mouse 4302.0 gene expression microarray. Red indicates upregulated expression, green indicates downregulated expression.

B Table of the top five most significantly enriched gene sets (based on GSEA enrichment and False Discovery Rate (FDR) $q$-value less than 0.25) in the TPC cell population. Hippo conserved signature genes found in the indicated gene set are listed in the last column.

C The Director's Challenge collection of lung cancer data sets was interrogated for expression of a gene signature upregulated in murine TPCs. Higher expression of the TPC signature (red) versus lower expression of the TPC signature (blue) was compared for patient metastasis (left) and overall survival (right).

D-G Expression of Yap1 (D), Taz (Wwtr1) (E), Nf2 (F) and Cyr61 (G) by qPCR in sorted TPC or non-TPC cells from Kras;p53-flox lung tumors. $n=8$ samples each.

$\mathrm{H}$ The Director's Challenge collection of lung cancer data sets was interrogated for expression of the Hippo conserved signature. Higher expression of the Hippo signature (red) versus lower expression of the Hippo signature (blue) was compared for patient metastasis (left) and overall survival (right).

Data information: ${ }^{*} P<0.05$. See also Supplementary Fig $\$ 4$ for additional data.

which has been shown to be important in lung development (Mitani et al, 2009), was over 2-fold overexpressed in the $\mathrm{Sca}^{+}$TPCs compared to Sca1 ${ }^{-}$cells (Fig 4E, $P=0.0087$ ). Importantly, the potent negative regulator of the Hippo pathway, $N f 2$, was greater than 15 -fold down-regulated in the $\mathrm{Scal}^{+}$cell population (Fig $4 \mathrm{~F}, P=0.0001$ ), while a known downstream target of activated Hippo signaling, cysteine-rich angiogenic inducer 61
(Cyr61), was over 2 -fold up-regulated in the $\mathrm{Scal}^{+}$cell population (Fig 4G, $P=0.021$ ). In the Director's Challenge cohort of lung adenocarcinoma patients, the Yap/Taz signature was significantly associated with worse overall survival $(P=0.00001)$ and with metastasis $(P=0.009) \quad($ Fig $4 \mathrm{H})$. These data show that Yap/Taz is associated with TPCs and human lung cancer progression. 
We next examined Yap1/Taz protein levels in tissue sections from murine lung cancer models, since differences in protein levels and localization of the Hippo transcriptional controllers may be more important than overall expression levels detected at the RNA level. Yap1/Taz activity is tightly controlled at the protein level: phosphorylated Yap1/Taz is sequestered in the cytoplasm and inactive, but dephosphorylated Yap1/Taz can translocate into the nucleus to activate target gene transcription. Using an antibody that recognizes both Yap1 and Taz proteins, we performed immunostaining of tumors from the non-metastatic Kras model (Jackson et al, 2001) and the Kras;p53-flox metastatic tumors. Interestingly, Yap1/Taz expression in Kras tumors was very weak and almost exclusively cytoplasmic (Fig $5 \mathrm{~A}, n=4$ ). In stark contrast, in Kras; p53-flox tumors $(n=4) \sim 30-50 \%$ of tumor cells expressed nuclear Yap1/Taz, and in lymph node metastases from Kras;p53-flox mice, almost all cells expressed nuclear Yap1/Taz $(n=3)$ (Fig 5A). These results supported the concept that Yap1/Taz expression and activity is correlated with more aggressive disease in lung cancer.

To determine if Yap activity is sufficient to affect lung tumor progression, we used a doxycycline-inducible, constitutively active allele of Yap1 in combination with oncogenic Kras in vivo. In tetO-YapS127A mice, a mutated version of Yap1 exhibits enhanced nuclear localization of Yap1 and constitutive signaling activity (Schlegelmilch et al, 2011). In a binary genetic approach, we activated Yap1 activity in lung tumor cells by treating Kras; Rosa26-LSL-rtTA; tetO-YapS127A mice with Adeno-Cre to initiate lung tumorigenesis, followed by treatment with doxycycline to activate Yap signaling concomitant with tumor initiation. Mice were euthanized when they showed signs of distress, 7 months after Adeno-Cre and doxycycline administration. Histological analysis showed that tumors of Kras; LSL-rtTA; tetO-YapS127A mice were significantly higher grade than those in Kras controls (CochranArmitage test, $P=0.04$, Fig 5B). Kras; LSL-rtTA; tetO-YapS127A mice had significantly more tumors than Kras controls (Fig 5C), but no difference in overall tumor burden, average tumor size, or Ki67 staining index (Fig 5D and E, Supplementary Fig S5A,B and C). These results indicated that Yap activation is sufficient to promote lung tumor progression in vivo.

We interrogated the role of Yap/Taz in metastatic capacity using in vitro migration and in vivo tail vein assays in the Kras;p53-flox cell lines after knockdown of Yap1/Taz. Two different shRNAs were used to reduce Yap1 or Taz levels to $40-80 \%$ of control levels (Supplementary Fig S5D and E). A significant reduction (1.5-3-fold compared to shGFP) in migration was observed in the shYap1 or shTaz cells exhibiting knockdown $(P<0.05)$ compared with the negative control shGFP (Fig 5F). To examine whether YAP knockdown in the human lung cancer cell line A549 would yield similar results, we interrogated the ability of two different doxycycline-inducible YAP shRNAs to affect cell migration. Dox-induced YAP knockdown resulted in significantly fewer migrated cells using both hairpins $(P=0.023$ and $P=0.020$ ); migration was over 2 -fold decreased in A549 YAP knockdown cells (Supplementary Fig S5F). Finally, tail vein injection was performed to assess the impact of knockdown on metastatic capacity in vivo. Lung metastases were significantly less frequent in recipients of shTaz cell lines compared to shGFP or shYap cells (shYap1108 $P=0.061$, shYap1824 $P=0.18$, shTaz771 $P=0.029$, shTaz1616 $P=0.0029$ ), and recipients of shTaz1616 cell lines in particular showed very few or no metastases or tumor burden (Fig 5G, Supplementary Fig S5G and H). Average tumor size was also smaller in shTaz recipients (Supplementary Fig S5I). These data indicated that Yap/Taz is necessary and sufficient to drive key steps in advanced lung tumorigenesis, including progression, migration, and metastasis.

To investigate the mechanism of Yap/Taz activity and to discover potential Taz targets in lung cancer cells, gene expression microarray analysis was performed. Three paired shGFP or shTaz Kras;p53-flox murine lung tumor cell lines (CK1750, SC241, and Tmet)(Supplementary Fig S6A) were compared; differentially expressed genes are listed in Supplementary Data. Gene Set Enrichment Analysis of the shTaz vs shGFP data was used to identify gene sets with negative enrichment scores, indicating cellular processes possibly impaired by Taz knockdown (Supplementary Fig S6B). The Yap/Taz gene signature (Cordenonsi et al, 2011) and genes differentially expressed in the Taz knockout mouse lungs (Mitani et al, 2009) were significantly enriched in the shTaz data set, validating our approach. qPCR confirmed differential expression of Cyr61, a known Yap/Taz target, and Ltbp4, a mediator of the TGF- $\beta$ pathway and possible Yap/Taz target, in SC241 shGFP and shTaz cells (Supplementary Fig S6C), further validating our gene expression data set. Published data sets connected to migration and metastasis (Lung Cancer Metastasis, Nguyen et al, 2009; Breast Cancer Invasion, Patsialou et al, 2012; Breast Cancer Migration, Gunawardane et al, 2005; Bladder Cancer Migration, Wu et al, 2008) were also enriched, validating the metastatic capacity associated with Yap/ Taz activity.

Gene sets of interest that were significantly enriched in shTaz cells revealed several pathways and activities that may be critical for Yap/Taz function in lung cancer progression and metastasis. Several gene sets associated with NF Kappa B signaling were significantly enriched: I KappaB Kinase NF KappaB Cascade, Regulation of I KappaB Kinase NF KappaB Cascade, and Positive Regulation of I KappaB Kinase NF KappaB Cascade (Supplementary Data). Expression of Bcl2, an NF-KB target that inhibits apoptosis, was validated for significantly decreased expression in shTaz cells (Supplementary Fig S6E). Gene sets corresponding to actin cytoskeletal processes were also highly decreased after Taz knockdown, including Actin Cytoskeleton, Cytoskeletal Protein Binding, Actin Binding, Actin Filament Binding, and Actin Filament Based Processes.

\section{Discussion}

Our results provide novel insight into the cells and pathways that drive the progression and metastasis of lung adenocarcinoma using TPCs as a discovery platform. TPCs expressing Sca1 and CD24 were enriched for metastatic activity after orthotopic transplantation. CD24 knockdown impaired metastatic processes including migration and ectopic tumor growth. Our findings also implicate a role for the Hippo signaling mediators Yap and Taz in lung TPCs and the progression and metastasis of lung cancer. Importantly, expression of TPC and Yap/Taz gene signatures predicted metastasis and patient survival, demonstrating the relevance of our findings in mouse models to human disease. These results delineate new ways to uncover clinically relevant mechanisms in advanced lung cancer.

Our data provide new understanding of the links between tumorpropagating cells and metastasis, an idea that has been postulated 
A
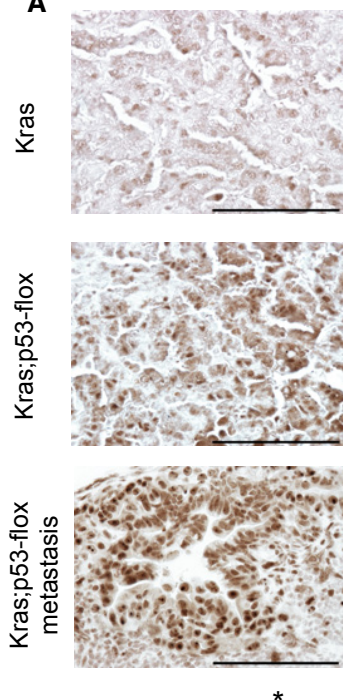

C
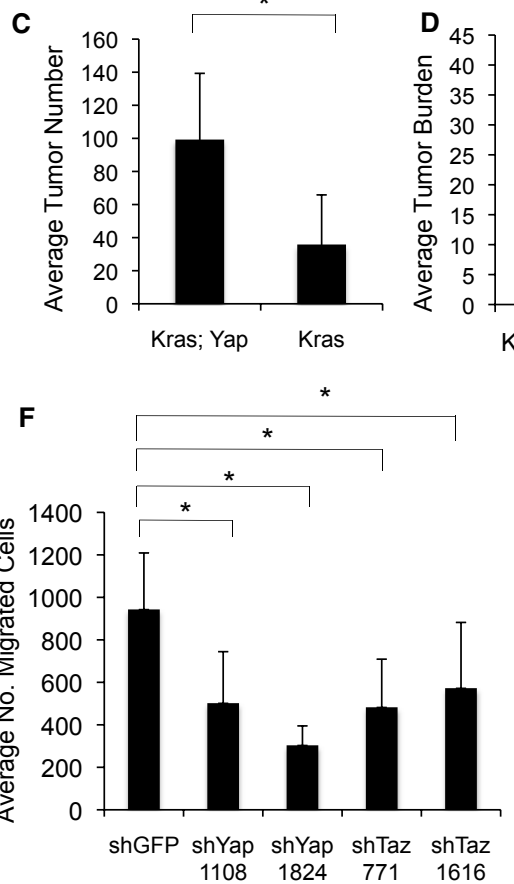

B
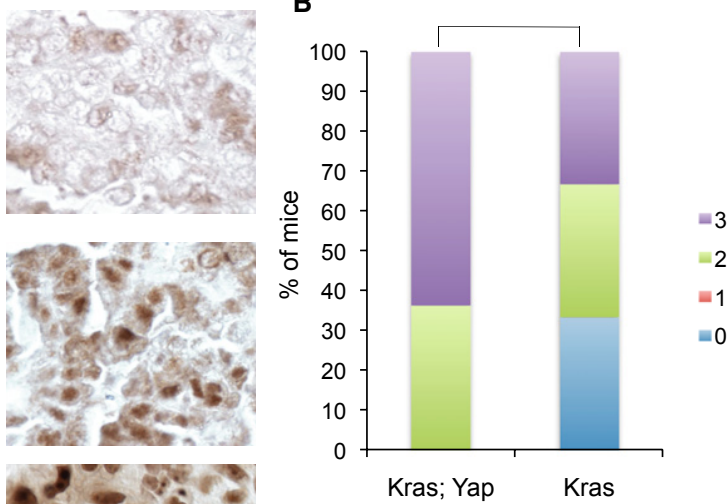

Tumor Grade
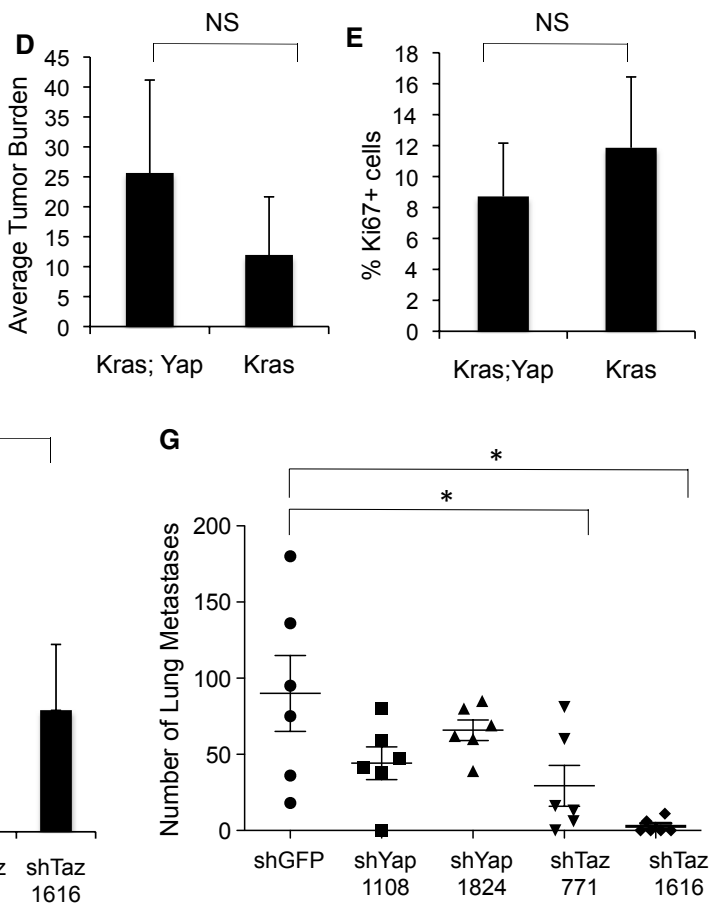

Figure 5. Yap/Taz function contributes to lung tumor progression and metastatic potential.

A Representative Yap1/Taz IHC (brown staining) in a Kras primary lung tumor (top), Kras;p53-flox tumor (middle), and Kras;p53-flox lymph node metastasis (bottom). 400× magnification, with zoom as shown, approximately $75 \mu \mathrm{m}$.

B Percentage of mice of each genotype with tumors of grade 0-4 scored from paraffin sections. Grade shown is the highest tumor grade present in each mouse. Grade 0 indicates no tumors present.

C Number of lung tumors per mouse was scored from paraffin sections and averaged for each genotype ( $n=15$ Kras mice, 14 Kras;Yap mice).

D Tumor burden was measured as the percentage of lung filled with tumors. Mice were euthanized 7 months after Cre or earlier if symptoms of lung tumors were apparent ( $n=15$ Kras mice, 14 Kras;Yap mice). NS, not significant.

E Percentage of Ki67 ${ }^{+}$cells per $200 \times$ field. NS, not significant.

F The average number of migratory cells observed in transwell migration assays, determined by the number of cells migrating towards serum-containing (10\% FBS) media in control, Yap1 or Taz knockdown CK1750 cells. Results shown are the average of three independent experiments.

G Average number of lung metastases after tail vein injection of CK1750 shGFP cells (circles), CK1750 shYap1 cells (squares, up triangles), or CK1750 shTaz cells (down triangles, diamonds). Lungs were analyzed for metastases 2 weeks after injection of 100,000 cells. Each symbol represents an individual mouse analyzed. Data shown are the combination of two independent experiments $(n=6)$.

Data information: ${ }^{*} P<0.05$, one-tailed $t$-test. See also Supplementary Fig $\$ 5$ for additional data. 
for at least a decade with limited experimental backing (reviewed in Adhikari et al, [2011]). The significant correlation of our TPC gene expression signature with both metastasis and patient survival adds new support for this proposition. Lung TPCs also exhibited downregulation of $N k \times 2.1$, a mechanism known to correspond with increased metastatic potential (Curtis et al, 2010; Winslow et al, 2011). We show that several TPC populations can produce metastatic lesions, albeit with differing degrees of activity; $\mathrm{Sca}^{+} \mathrm{CD} 24^{+}$cells were more metastatic than $\mathrm{Sca} 1^{-} \mathrm{CD} 24^{+}$cells. Differing from our work, tumor cell barcoding studies in colon cancer showed that only one TPC fraction contributed to metastases (Dieter et al, 2011). Therefore, in some tumor types one unique metastasis-propagating cell population may exist, whereas our data suggest a gradient of metastatic capacity exists within lung tumor cell populations.

CD24 appears to be required for lung TPCs to propagate tumors and possibly to drive a metastatic cascade. CD24 expression levels were similar in lung tumors arising in recipient mice after transplantation of $\mathrm{CD} 24^{+}$or $\mathrm{CD} 24^{-}$cells; it is possible that activation of CD24 expression is critical during a particular stage of tumorigenesis or metastatic progression. Furthermore, results in bladder (Overdevest et al, 2011) and liver (Lee et al, 2011) cancer, in combination with the present study, make a strong argument for CD24 being a marker and functional mediator of metastatic potential in multiple tumor types. As proliferation and apoptosis were not significantly altered in CD24 knockdown cells, the mechanism by which CD24 affects tumorigenesis and metastasis remains to be determined.

We demonstrate for the first time that Yap/Taz are active in lung-tumor propagating cells with metastatic potential, and that Yap activation affects lung tumor progression in a mouse model in vivo. Interestingly, the Yap/Taz gene signature predicted lung cancer patient metastasis and survival. Taz expression was also found to be significantly associated with poor differentiation, poor survival, and metastasis in patients with non-small cell lung cancer (Xie et al, 2012). Previously, Yap1 and Taz have both been implicated in different processes of lung development and disease (see also Introduction). Taz interacts with the master transcription factor Nkx2.1 during mouse lung development to promote alveolarization (Mitani et al, 2009). These and our own observations of elevated Taz expression in TPCs and decreased lung metastases from tail vein injections after knockdown of Taz tempt us to speculate that Taz, rather than Yap1, is primarily utilized by lung tumors to promote metastasis. Supporting this idea, Taz may regulate the cancer stem cell phenotype in breast cancers (Cordenonsi et al, 2011). In our studies, constitutive mutant Yap was sufficient to significantly impact Kras-driven lung tumor progression, yet metastasis did not develop in Kras;Yap mice. Notably, the presence of more high-grade tumors in Kras;Yap mice required euthanasia and may have precluded our ability to assess later metastatic progression. It is also possible that further activation of Yap1 through mutation at more than one site is necessary to drive metastases. It remains possible that both Yap1 and Taz play important and complementary roles in lung TPC function and metastatic potential.

Yap/Taz may control lung cancer cell migration and metastasis through a number of mechanisms implicated in this study. In tail vein assays, the average tumor size was significantly less in recipients of shTaz cells vs shGFP cells, pointing to the potential importance of Taz regulation of proliferation in advanced lung tumors.
Supporting this idea, we found many gene sets enriched for cell growth in shTaz cells. GSEA also suggested a role for Taz regulation of the NF-KappaB pathway, which has been shown to be required for Kras;p53-flox lung tumorigenesis (Meylan et al, 2009; Xue et al, 2011). Further studies are needed to which, if any, of the cellular activities identified in our expression analyses are critical for Yap/ Taz contribution to aggressive lung cancer.

It will be important to understand the cellular markers and mechanistic drivers of metastatic cancer cells in each tumor type of interest. In bladder cancer, $\mathrm{CD} 24^{+}$cells rely on the STAT3/NANOG network to promote metastasis (Lee et al, 2011), whereas $\mathrm{CD}_{2} 4^{+}$cells utilize the SRC-family kinase YES in metastatic melanoma (Liu et al, 2012). Additionally, we show here that Yap/Taz activity may mediate lung cancer metastasis in lung TPCs. It remains to be determined if there is a direct interaction between $\mathrm{CD} 24$ and Yap1/Taz regulation in lung tumorigenesis, since we found that these molecules were all required for lung cancer cell metastatic behavior. Interestingly, Hippo signaling has been implicated in regulation of expression of CD44, another surface marker of tissue-specific TPCs such as in breast cancer (Xu et al, 2010; Cordenonsi et al, 2011). Although there may be overlap between the markers and pathways responsible for metastasis in different tumor types, many combinations are likely utilized by aggressive cancer cells. Synergistic investigations into the phenotype of cells that are responsible for metastatic spread of lung cancer and the pathways that mediate this progression should ultimately lead to new ways to target the most functionally important and deadly lung cancer cells.

\section{Materials and Methods}

\section{Generation of cell lines and in vitro assays}

CK1750 and SC241 cells were generated by culturing tumor cells from a Kras;p53-flox donor mouse in DMEM $+10 \%$ FBS. Tmet cells were obtained from Monte Winslow (Winslow et al, 2011). These cells were infected with lentiviral constructs from The RNAi Consortium, pLKO.1 based system. The two hairpins directed at CD24a were TRCN0000077028 (shCD24a-1) and TRCN0000077032 (shCD24a-5), the two hairpins directed at Yap1 were TRCN0000095866 (Yap1108) and TRCN0000095864 (Yap1824), the two hairpins directed at Taz were TRCN0000095949 (Taz1616) and TRCN0000095951 (Taz771), with a non-targeting hairpin directed against GFP (Sigma SHC005) as a control. Transduced cells were selected with $3 \mu \mathrm{g} / \mathrm{ml}$ puromycin for $1-2$ weeks. Knockdown was confirmed by quantitative RT-PCR and flow cytometry. To generate shCD24-Low-1 and shcD24-Low-5 cell lines, sorts for the lowest CD24-expressing cells were completed. All lines were maintained in DMEM $+10 \%$ FBS. 24-well format cell migration assays (Corning) were performed as per the manufacturer's instructions. Briefly, cells were serum-starved overnight, harvested with Accutase (Millipore) and counted. Cells were plated in serum-free conditions $(30,000$ cells per well) on the top chambers and the bottom chambers contained either serum-free DMEM or DMEM $+10 \%$ FBS. After a $24 \mathrm{~h}$ incubation, non-migratory cells were removed using a cotton swab, migratory cells were stained with DAPI for imaging and nuclei were counted using ImageJ. All conditions were completed with three to four replicates and averaged. 


\section{Mice and tissues}

Lox-Stop-Lox-Kras ${ }^{G 12 D} ; p 53^{f l f l}$ and Lox-Stop-Lox-Kras ${ }^{G 12 D}$ mice (Jackson et al, 2001, 2005) were maintained in virus-free conditions on 129 SvJae background. Lox-Stop-Lox-Kras ${ }^{G 12 D}$;Lox-Stop-Lox-rtTA; tetO-YapS127A mice were maintained in virus-free conditions on a mixed 129/C57Bl6 background. All mouse experiments were approved by the $\mathrm{BCH}$ Animal Care and Use Committee and by the Dana-Farber Cancer Institute Institutional Animal Care and Use Committee, both accredited by AAALAC, and were performed in accordance with relevant institutional and national guidelines and regulations. Lung tissue preparation was as described (Curtis et al, 2010) and sections were analyzed for tumors by at least two investigators including a pathologist with expertise in murine lung cancer. Tumor burden, the percentage of lung filled with tumor, was calculated using ImageJ to measure total lung and tumor area from H\&E stained paraffin sections from each mouse. Tumor size was measured using ImageJ to quantify tumor area from paraffin sections and the average area of all lung tumors per mouse was calculated. For metastases, heart, liver, spleen, kidneys, lymph nodes, and chest wall were also analyzed. Immunohistochemistry was performed as described (Schlegelmilch et al, 2011) with anti-Yap1 (1:50, Cell Signaling \#4912) or anti-Ki67 (1:10,000, Novocastra) antibodies and developed using Vectastain Elite ABC kit (Vector Labs). Immunofluorescent staining for pro-SPC was performed with anti-pro-SPC (1:500, Chemicon). Imaging was performed with a Nikon 90i camera and NIS-Elements software and processed with NIS-Elements and Adobe Photoshop.

\section{FACS analysis and sorting}

Mice were euthanized with avertin overdose and lungs were dissected and examined grossly for tumor formation. Tumors were dissected from the lungs of primary mice and tumor tissue was prepared as described (Curtis et al, 2010). Briefly, tumors were isolated, minced, digested rotating for $1 \mathrm{~h}$ at $37^{\circ} \mathrm{C}$ with $2 \mathrm{mg} / \mathrm{ml}$ Collagenase/Dispase (Roche) and then filtered twice $(100 \mu \mathrm{m}$, then $40 \mu \mathrm{m}$ ) after a 5-minute incubation with $0.025 \mathrm{mg} / \mathrm{ml}$ DNase. Cell lines were trypsinized and then filtered $(40 \mu \mathrm{m})$. Single-cell suspensions were stained using Sca1-FITC, -PE, or APC-Cy7, CD45-APC, CD31-APC, CD24-Biotin (with Streptavidin-APC/Cy7) or -FITC (BD Pharmingen) with 7AAD (Molecular Probes) or DAPI (Sigma) staining to visualize dead cells. All antibodies were incubated for 15-20 minutes at 1:100 dilutions for primaries and 1:200 for secondaries. Cell sorting was performed with a Beckman Coulter/ Cytomation MoFlo or a BD FACS Aria, and data were analyzed with FlowJo software (Tree Star, Inc.).

\section{Tumor transplants}

Intratracheal transplants were performed as described (Curtis et al, 2010). Mice were monitored for signs of lung tumor onset and euthanized for gross and histological analysis upon signs of distress. Cells for tail vein injections were resuspended in PBS and mice were sacrificed 2 weeks after injection for analysis of lung metastasis. Cells for subcutaneous injections were resuspended in a 1:1 mixture of PBS and matrigel (BD Biosciences), and subcutaneous tumor volume was measured (volume $=$ length $\times$ width $\times$ depth).

\section{Quantitative RT-PCR gene expression analysis}

RNA from sorted cell populations was extracted from 8-12 tumors using the Stratagene Absolutely RNA Nanoprep Kit. cDNA was made using the SuperScript III kit (Invitrogen) and analyzed using TaqMan Assays (Applied Biosystems) for Acta2 (Mm00725412_s1), Bcl2 (Mm00477631_m1), Cd24a (Mm00782538_sH), Cdh1 (Mm0124 7357_m1), Cyr61 (Mm00487498_m1), Ltbp4 (Mm00723631_m1), Nf2 (Mm00477771_m1), Vim (Mm01333430_m1), Wwtr1 (Mm0128 9583_m1), Yap1 (Mm01143263_m1), or YAP1 (Hs00902712_g1), with a BioRad iQ5 iCycler or StepOnePlus ${ }^{\mathrm{TM}}$ Real-Time PCR System (Applied Biosystems) and software as per the manufacturer's recom mendations. Mouse Actb (B-actin, 4352341E) or Gapdh (4352339E) was used as an endogenous control for normalization.

\section{Microarray analysis}

For $\mathrm{Sca}^{+} / \mathrm{Sca1}^{-}$arrays, four primary tumors from Kras;p53-flox mice were dissociated and sorted into $\mathrm{CD} 31^{-} / \mathrm{CD} 45^{-} / \mathrm{Sca} 1^{-}$and $\mathrm{CD} 31^{-} / \mathrm{CD} 45^{-} / \mathrm{Scal}^{+}$populations. RNA was isolated as above and subsequently amplified using the WT-Ovation Pico kit (NuGEN). The amplified cDNA was fragmented and biotin labeled using the FL-Ovation Biotin V2 kit (NuGEN). The Children's Hospital Boston Molecular Genetics Core Facility performed the hybridization and data acquisition using an Affymetrix Mouse Genome 4302.0 expression array. Array normalization, expression value calculation and clustering analysis were performed using DNA-Chip Analyzer (www.dchip.org, Schadt et al, 2001). The Invariant Set Normalization method was used to normalize arrays at probe cell level to make them comparable, and the model-based method was used for probe-selection and computing expression values. These expression levels were attached with standard errors as measurement accuracy, which were subsequently used to compute $90 \%$ confidence intervals of fold changes between the Sca1 ${ }^{+}$and Sca1 ${ }^{-}$groups. The lower confidence bounds of fold changes were conservative estimate of the real fold changes. Genes with more than 2 -fold increased expression in $\mathrm{Sca}^{+}$cells relative to Sca1 ${ }^{-}$cells and an associated $P$-value of 0.02 were selected for further study $\left(\mathrm{Scal}^{+}\right.$up gene signature, Supplemental Data). The Affymetrix probe match tool was used for matching the Sca1 ${ }^{+}$up gene list to human U133A probes (Supplemental Data). Gene set enrichment analysis (GSEA) was performed by the Center for Computational Cancer Biology at the Dana Farber Cancer Institute with the pre-ranked implementation of the GSEA software package (Subramanian et al, 2005) using the moderated $t$-statistic from limma to determine rank order (Smyth, 2004).

shGFP/shTaz Arrays were performed in the Boston Children's Hospital Molecular Genetics Core facility on Affymetrix mouse Gene2.0ST slides. Array quality was assessed using the R/Bioconductor package (http://www.bioconductor.org/). Raw CEL files from U133A Affymetrix arrays were processed using the robust multi-array average (RMA) algorithm (Irizarry et al, 2003). To identify genes correlating with the phenotypic groups, we used limma (Smyth, 2004) to fit a statistical linear model to the data and then tested for differential gene expression in the two groups: shTaz (SC241, CK1750 and Tmet) vs shGFP (SC241, CK1750 and Tmet). GSEA (Subramanian et al, 2005) was performed using the javaGSEA desktop application on pre-ranked gene lists constructed from RMA normalized expression data. 


\section{Human tumor data Kaplan-Meier analysis}

Raw gene expression data from human lung adenocarcinoma samples were obtained from publications (Director's Challenge, 2008; Chitale et al, 2009, http://cbio.mskcc.org/Public/lung_array_data/). Among these datasets, 3 are annotated for survival post biopsy while 1 dataset is annotated for both survival and metastatic spread of disease. Probes intensities from the Affymetrix U133A platform used in these studies were normalized and modeled using dChip software. Kaplan-Meier survival analyses were implemented after the samples were hierarchically clustered using centroid linkage into two risk groups using either the human orthologues of the $\mathrm{Scal}^{+}$up gene set or the Yap/Taz conserved gene set (Cordenonsi et al, 2011). Differences of the survival risk between the two risk groups were assessed using the Mantel-Haenszel log rank test. The larger area between the two risk groups and its associated smaller $P$-value from the Mantel-Haenszel log rank test implicate a better classification model. For the dataset for which metastatic spread was annotated, both survival and metastatic spread of the two risk groups were queried.

\section{Statistical analysis}

Except where indicated, Student's $t$-test was used to compare measurements between two conditions. For tumor cell transplants, data organized in tables was analyzed using Fisher's exact test. GraphPad Prism (GraphPad Software, Inc.), Excel and Mstat (McArdle Laboratory for Cancer Research, University of Wisconsin) were used for graphing and statistical analyses. Unless noted otherwise, pooled data is represented by the mean and standard deviation. P-values less than 0.05 with a one-tailed distribution were considered significant.

Supplementary information for this article is available online: http://emboj.embopress.org

\section{Acknowledgements}

We thank the DFCI, BIDMC, and CHB HemOnc FACS facilities, M. Correll and S. Duan of the DFCl Center for Computational Cancer Biology, and members of the Kim Lab for technical assistance and discussions, R. Bronson for histopathology, L. Zon, C. Cepko, S. Armstrong, and W. Hahn for helpful discussions. This work was supported by DoD, Air Force Office of Scientific Research, National Defense Science and Engineering Graduate Fellowships, 32 CFR 168a (to S.J.C. and A.N.L.), PF-09-121-01-DDC and PF-12151-01-DMC from the American Cancer Society (to K.W.S. and C.M.F., respectively), the Ladies Auxilliary to the Veterans of Foreign Wars (to C.M.F.), Dana Farber Harvard Cancer Center Lung Cancer SPORE grant P50 CA090578, R01 AG2400401, R01 CA122794, R01 CA140594 (to K-K.W.), the $\checkmark$ Foundation for Cancer Research, American Cancer Society Research Scholar Grant \#RSG-08-082-01-MGO, the Freeman Trust, the Harvard Stem Cell Institute, NIH/NHLBI U01 HL100402 and R01 HL090136 and The Lung Cancer Alliance (to C.F.K.).

\section{Author contributions}

ANL, SJC, SPR, MM, DEW, DTM, KWS, and JB performed experiments and analyzed results. CMF performed bioinformatic analyses. ANL, AMB and JB managed mouse colony. ZEW, DJW, KKW, and FDC generated mice and/or reagents. ANL, SJC, DEW and CFK designed experiments. ANL and CFK wrote the article.

\section{Conflict of interest}

The authors declare that they have no conflict of interest.

\section{References}

Adhikari AS, Agarwal N, Iwakuma T (2011) Metastatic potential of tumor-initiating cells in solid tumors. Front Biosci 16: 1927-1938

Al-Hajj M, Wicha MS, Benito-Hernandez A, Morrison SJ, Clarke MF (2003) Prospective identification of tumorigenic breast cancer cells. Proc Natl Acad Sci USA 100: 3983-3988

Bertolini G, Roz L, Perego P, Tortoreto M, Fontanella E, Gatti L, Pratesi G, Fabbri A, Andriani F, Tinelli S, Roz E, Caserini R, Lo Vullo S, Camerini T, Mariani L, Delia D, Calabro E, Pastorino U, Sozzi G (2009) Highly tumorigenic lung cancer CD133 + cells display stem-like features and are spared by cisplatin treatment. Proc Natl Acad Sci USA 106: 16281-16286

Charafe-Jauffret E, Ginestier C, Iovino F, Tarpin C, Diebel M, Esterni B, Houvenaeghel G, Extra JM, Bertucci F, Jacquemier J, Xerri L, Dontu G, Stassi G, Xiao Y, Barsky SH, Birnbaum D, Viens P, Wicha MS (2010) Aldehyde dehydrogenase 1-positive cancer stem cells mediate metastasis and poor clinical outcome in inflammatory breast cancer. Clin Cancer Res 16: $45-55$

Charafe-Jauffret E, Ginestier C, Iovino F, Wicinski J, Cervera N, Finetti P, Hur MH, Diebel ME, Monville F, Dutcher J, Brown M, Viens P, Xerri L, Bertucci F, Stassi G, Dontu G, Birnbaum D, Wicha MS (2009) Breast cancer cell lines contain functional cancer stem cells with metastatic capacity and a distinct molecular signature. Cancer Res 69: 1302-1313

Chen YC, Hsu HS, Chen YW, Tsai TH, How CK, Wang CY, Hung SC, Chang YL, Tsai ML, Lee YY, Ku HH, Chiou SH (2008) Oct-4 expression maintained cancer stem-like properties in lung cancer-derived CD133-positive cells. PLOS ONE 3: e2637

Chitale D, Gong Y, Taylor BS, Broderick S, Brennan C, Somwar R, Golas B, Wang L, Motoi N, Szoke J, Reinersman JM, Major J, Sander C, Seshan VE, Zakowski MF, Rusch V, Pao W, Gerald W, Ladanyi M (2009) An integrated genomic analysis of lung cancer reveals loss of DUSP4 in EGFR-mutant tumors. Oncogene 31: 2773-2783

Cordenonsi M, Zanconato F, Azzolin L, Forcato M, Rosato A, Frasson C, Inui M, Montagner M, Parenti AR, Poletti A, Daidone MG, Dupont S, Basso G, Bicciato S, Piccolo S (2011) The Hippo Transducer TAZ Confers Cancer Stem Cell-Related Traits on Breast Cancer Cells. Cell 147: $759-772$

Croker AK, Goodale D, Chu J, Postenka C, Hedley BD, Hess DA, Allan AL (2009) High aldehyde dehydrogenase and expression of cancer stem cell markers selects for breast cancer cells with enhanced malignant and metastatic ability. J Cell Mol Med 13: 2236-2252

Curtis SJ, Sinkevicius KW, Li D, Lau AN, Roach RR, Zamponi R, Woolfenden AE, Kirsch DG, Wong KK, Kim CF (2010) Primary tumor genotype is an important determinant in identification of lung cancer propagating cells. Cell Stem Cell 7: 127-133

Damelin M, Geles KG, Follettie MT, Yuan P, Baxter M, Golas J, Dijoseph JF, Karnoub M, Huang S, Diesl V, Behrens C, Choe SE, Rios C, Gruzas J, Sridharan L, Dougher M, Kunz A, Hamann PR, Evans D, Armellino D et al (2011) Delineation of a cellular hierarchy in lung cancer reveals an oncofetal antigen expressed on tumor-initiating cells. Cancer Res 71 : $4236-4246$ 
Dieter SM, Ball CR, Hoffman CM, Nowrouzi A, Herbst F, Zavidij O, Abel U, Arens A, Weichert W, Brand K, Koch M, Weitz J, Schmidt M, von Kalle C, Glimm H (2011) Distinct types of tumor-initiating cells form human colon cancer tumors and metastases. Cell Stem Cell 9: 357-365

Director's Challenge Consortium for the Molecular Classification of Lung Adenocarcinoma, Shedden K, Taylor JM, Enkemann SA, Tsao M, Yeatman TJ, Gerald WL, Eschrich S, Jurisica I, Giodano TJ, Misek DE, Chang AC, Zhu CQ, Strumpf D, Hanash S, Shepherd FA, Ding K, Seymour L, Naoki K, Pennell N, Weir B et al (2008) Gene expression-based survival prediction in lung adenocarcinoma: a multi-site, blinded validation study. Nat Med 14: $822-827$

Eramo A, Lotti F, Sette G, Pilozzi E, Biffoni M, Di Virgilio A, Conticello C, Ruco L, Peschle C, De Maria R (2008) Identification and expansion of the tumorigenic lung cancer stem cell population. Cell Death Differ 15: 504-514

Gunawardane RN, Sgroi DC, Wrobel CN, Koh E, Daley GQ, Brugge JS (2005) Novel role for PDEF in epithelial cell migration and invasion. Cancer Res 65: $11572-11580$

Hermann PC, Huber SL, Herrler T, Aicher A, Ellwart JW, Guba M, Bruns C], Heeschen C (2007) Distinct populations of cancer stem cells determine tumor growth and metastatic activity in human pancreatic cancer. Cell Stem Cell 1: 313-323

Ignatius MS, Chen E, Elpeck NM, Fuller AZ, Tenente IM, Clagg R, Liu S, Blackburn JS, Linardic CM, Rosenberg AE, Nielsen PG, Mempel TR, Langenau DM (2012) In Vivo imaging of tumor-propagating cells, regional tumor heterogeneity, and dynamic cell movements in embryonal rhabdomyosarcoma. Cancer Cell 21: 680-693

Irizarry RA, Hobbs B, Collin F, Beazer-Barclay YD, Antonellis KJ, Scherf U, Speed TP (2003) Exploration, normalization, and summaries of high density oligonucleotide array probe level data. Biostatistics 4 $249-264$

Jackson EL, Olive KP, Tuveson DA, Bronson R, Crowley D, Brown M, Jacks T (2005) The differential effects of mutant p53 alleles on advanced murine lung cancer. Cancer Res 65: 10280-10288

Jackson EL, Willis N, Mercer K, Bronson RT, Crowley D, Montoya R, Jacks T, Tuveson DA (2001) Analysis of lung tumor initiation and progression using conditional expression of oncogenic K-ras. Genes Deu 15: 3243-3248

Korkaya H, Paulso A, lovino F, Wicha MS (2008) HER2 regulates the mammary stem/progenitor cell population driving tumorigenesis and invasion. Oncogene 27: 6120-6130

Kristiansen G, Schluns K, Yongwei Y, Denkert C, Dietel M, Petersen I (2003) CD24 is an independent prognostic marker of survival in nonsmall cell lung cancer patients. Br J Cancer 88: 231-236

Lee HJ, Choe G, Jheon S, Sung SW, Lee CT, Chung JH (2010) CD24, a novel cancer biomarker, predicting disease-free survival of non-small cell lung carcinomas: a retrospective study of prognostic factor analysis from the viewpoint of forthcoming (seventh) new TNM classification. J Thorac Oncol 5: 649-657

Lee TK, Castilho A, Cheung VC, Tang KH, Ma S, Ng IO (2011) CD24(+) liver tumor-initiating cells drive self-renewal and tumor initiation through STAT3-mediated NANOG regulation. Cell Stem Cell 9: 50-63

Levina V, Marrangoni AM, DeMarco R, Gorelik E, Lokshin AE (2008) Drug-selected human lung cancer stem cells: cytokine network, tumorigenic and metastatic properties. PLOS ONE 3: e3077

Liu W, Monahan KB, Pfefferle AD, Shimamura T, Sorrentiono J, Chan K, Roadcap DW, Ollila DW, Thomas NE, Castrillon DH, Miller CM, Perour CM, Wong KK, Bear JE, Sharpless NE (2012) LKB1/STK11 inactivation leads to expansion of a pro-metastatic tumor sub-population in melanoma. Cancer Cell 21: 751-764
Malanchi I, Santamaria-Martínez A, Susanto E, Peng H, Lehr HA, Delaloye JF, Huelsken J (2011) Interactions between cancer stem cells and their niche govern metastatic colonization. Nature 481: 85-89

Meylan E, Dooley AL, Feldser DM, Shen L, Turk E, Ouyang C, Jacks T (2009) Requirement for NF-KappaB signaling in a mouse model of lung adenocarcinoma. Nature 462: 104-107

Mitani A, Nagase T, Fukuchi K, Aburatani H, Makita R, Kurihara H (2009) Transcriptional coactivator with PDZ-binding motif is essential for normal alveolarization in mice. Am J Respir Crit Care Med 180: 326-338

Nguyen DX, Chiang AC, Zhang XH, Kim JY, Kris MG, Ladanyi M, Gerald WL, Massague J (2009) WNT/TCF signaling through LEF1 and HOXB9 mediates lung adenocarcinoma metastasis. Cell 138: 51-62

Overdevest JB, Thomas S, Kristiansen G, Hansel DE, Smith SC, Theodorescu D (2011) CD24 offers a therapeutic target for control of bladder cancer metastasis based on a requirement for lung colonization. Cancer Res 71 : $3802-3811$

Pan D (2010) The hippo signaling pathway in development and cancer. Dev Cell 19: $491-505$

Pang R, Law WL, Chu AC, Poon JT, Lam CS, Chow AK, Ng L, Cheung LW, Lan XR, Lan HY, Tan VP, Yau TC, Poon RT, Wong BC (2010) A subpopulation of CD26 + cancer stem cells with metastatic capacity in human colorectal cancer. Cell Stem Cell 6: 603-615

Patsialou A, Wang Y, Lin J, Whitney K, Goswami S, Kenny PA, Condeelis JS (2012) Selective gene-expression profiling of migratory tumor cells in vivo predicts clinical outcome in breast cancer patients. Breast Cancer Res 14: R129

Pisters KM, Ginsberg RJ, Giroux DJ, Putnam JB, Kris MG, Johnson DH, Roberts JR, Mault J, Crowley JJ, Bunn PA (2000) Induction chemotherapy before surgery for early-stage lung cancer: A novel approach. Bimodality Lung Oncology Team. J Thorac Cardiovasc Surg 119: 429-439

Schadt EE, Li C, Ellis B, Wong WH (2001) Feature extraction and normalization algorithms for high-density oligonucleotide gene expression array data. J Cell Biochem Suppl 37: 120-125

Schlegelmilch K, Mohseni M, Kirak O, Pruszak J, Rodriguez JR, Zhou D, Kreger BT, Vasioukhin V, Avruch J, Brummelkamp TR, Camargo FD (2011) Yap1 acts downstream of alpha-catenin to control epidermal proliferation. Cell 144: $782-795$

Shipitsin M, Campbell LL, Argani P, Weremowicz S, Bloushtain-Qimron N, Yao J, Nikolskaya T, Serebryiskaya T, Beroukhim R, Hu M, Halushka MK, Sukumar S, Parker LM, Anderson KS, Harris LN, Garber JE, Richardson AL, Schnitt SJ, Nikolsky Y, Gelman RS et al (2007) Molecular definition of breast tumor heterogeneity. Cancer Cell 11: 259-273

Siegel R, Naishadham D, Jemal A (2013) Cancer statistics, 2013. CA Cancer J Clin 63: 11-30

Smyth GK (2004) Linear models and empirical bayes methods for assessing differential expression in microarray experiments. Stat Appl Genet Mol Biol 3: 3

Subramanian A, Tamayo P, Mootha VK, Mukherjee S, Ebert BL, Gillette MA, Paulovich A, Pomeroy SL, Golub TR, Lander ES, Mesirov JP (2005) Gene set enrichment analysis: a knowledge-based approach for interpreting genome-wide expression profiles. Proc Natl Acad Sci USA 102: $15545-15550$

Wang Y, Dong Q, Zhang Q, Li Z, Wang E, Qiu X (2010) Overexpression of yes-associated protein contributes to progression and poor prognosis of non-small-cell lung cancer. Cancer Sci 101: 1279-1285

Winslow MM, Dayton TL, Verhaak RG, Kim-Kiselak C, Snyder EL, Feldser DM, Hubbard DD, DuPage MJ, Whittaker CA, Hoersch S, Yoon S, Crowley D, Bronson RT, Chiang DY, Meyerson M, Jacks T (2011) Suppression of lung adenocarcinoma progression by Nk2-1. Nature 473: 101-104 
Wu Y, Siadaty MS, Berens ME, Hampton GM, Theodorescu D (2008) Overlapping gene expression profiles of cell migration and tumor invasion in human bladder cancer identify metallothionein $1 \mathrm{E}$ and nicotinamide $\mathrm{N}$-methyltransferase as novel regulators of cell migration. Oncogene 27: $6679-6689$

Xie M, Zhang L, He CS, Hou JH, Lin SX, Hu ZH, Xu F, Zhao HY (2012) Prognostic significance of TAZ expression in resected non-small cell lung cancer. J Thorac Oncol 7: 799-807

Xu Y, Stamenkovic I, Yu Q (2010) CD44 attenuates activation of the hippo signaling pathway and is a prime therapeutic target for glioblastoma. Cancer Res 70: 2455 - 2464

Xue W, Meylan E, Oliver TG, Feldser DM, Winslow MM, Bronson R, Jacks T (2011) Response and resistance to NF-kB inhibitors in mouse models of lung adenocarcinoma. Cancer Discou 1: 236-247
Yao X, Labelle M, Lamb CR, Dugan JM, Williamson CA, Spencer DR, Christ KR, Keating RO, Lee WD, Paradis CA, Begum S, Hynes RO, Wittrup KD (2013) Determination of 35 cell surface antigen levels in malignant pleural effusions identifies CD24 as a marker of disseminated tumor cells. Int J Cancer 133: $2925-2933$

Zheng Y, de la Cruz CC, Sayles LC, Alleyne-Chin C, Vaka D, Knaak TD, Bigos M, XU Y, Hoang CD, Shrager JB, Fehling HJ, French D, Forrest W, Jiang Z, Carano RA, Barck KH, Jackson EL, Sweet-Cordero EA (2013) A rare population of CD24(+)ITCB4(+)Notch(hi) cells drives tumor propagation in NSCLC and requires Notch 3 for self-renewal. Cancer Cell 24: $59-74$

Zhou Z, Hao Y, Liu N, Raptis L, Tsao MS, Yang X (2011) TAZ is a novel oncogene in non-small cell lung cancer. Oncogene 30: $2181-2186$ 